\title{
ESCOLA SEM PARTIDO: DO CONTROLE À ESPOLIAÇÃO
}

\author{
SCHOOL WITHOUT PARTY: FROM CONTROL TO DISPOSSESSION
}

ESCUELA SIN PARTIDO: DEL CONTROL A LA DESPOSESIÓN

\author{
Denis Castilho - Universidade Federal de Goiás - Goiânia, Goiás, Brasil \\ deniscastilho@hotmail.com
}

\section{Resumo}

A primeira proposta do Escola Sem Partido (ESP) foi elaborada em 2004. Dez anos depois, com a eclosão de mobilizações e movimentos conservadores pelo Brasil, ganhou repercussão e forte apoio de parlamentares e de partidos de direita. Alegando provável doutrinação esquerdista nas escolas, autoproclamando-se apartidário e polemizando temas relativos às diretrizes educacionais, o movimento ampliou suas frentes de ação, e projetos de lei do ESP foram apresentados na Câmara dos Deputados e em Assembleias Legislativas de vários estados do país. Uma análise desses projetos e das concepções defendidas por seus apoiadores, conforme evidenciamos neste texto, revela outras faces do movimento. Os interesses implícitos, a disputa partidária, 0 vínculo com tendências totalitárias que instigam o cerceamento do trabalho docente e a ligação com um projeto mais amplo que visa fazer da escola um grande negócio via espoliação, acende um alerta e suscita um amplo debate sobre os reais interesses do ESP e suas implicações à educação do país. Essa discussão é fundamental para a construção de um contraponto mais eficiente, baseado no esclarecimento, no protagonismo e na luta por uma escola mais autônoma e democrática.

Palavras-chave: Escola Sem Partido. Controle. Educação. Espoliação.

\section{Abstract}

The Escola Sem Partido (ESP) movement, or School Without Party, was initially proposed in Brazil in 2004. Ten years later, with the emergence of conservative rallies and gatherings nationwide, it gained notoriety and strong support from members of Congress as well as from right-wing parties. Grounded on the belief that Brazilian schools probably harbour leftist indoctrination and claiming a non-partisan profile, in addition to sparking controversy over educational guidelines, the ESP has recently increased its ranks and several bills have been put forward in the Chamber of Deputies and in many state legislative assemblies. An analysis of these bills and of the central claims backed by ESP supporters reveals another side to the movement, as this paper shows. Factors including ESP's covert interests, partisan disputes, a link with authoritarian tendencies that call for curtailing teachers' work, as well as a connection with a broader project that aims to turn schools into a business enterprise via dispossession, raise serious questions and a general discussion regarding the movement's real interests and their implications for Brazil's educational system. Such a discussion is vital for establishing a more effective counterargument, based on informed knowledge, on leadership, and on the fight for a more autonomous and democratic school.

Keywords: Escola Sem Partido. Control. Education. Dispossession.

\section{Resumen}

El proyecto Escola Sem Partido (ESP), o Escuela sin partido, se propuso inicialmente en Brasil en 2004. Diez años después, con la eclosión de movilizaciones y movimientos conservadores en Brasil, ganó repercusión y fuerte apoyo de parlamentarios y de partidos de derecha. Alegando probable adoctrinamiento izquierdista en las escuelas, autoproclamándose apartidario y polemizando temas relativos a las directrices educativas, el movimiento amplió sus frentes de acción, y los proyectos de ley del ESP se presentaron en la Cámara de los Diputados y en las Asambleas Legislativas de varios estados del país. Un análisis de esos proyectos y de 
las concepciones defendidas por sus partidarios, como evidenciamos en este texto, revela otras caras del movimiento. Los intereses implícitos, la disputa partidista, el vínculo con tendencias totalitarias que instigan la intimidación del trabajo docente y la relación con un proyecto más amplio que busca hacer de la escuela un gran negocio vía desposesión, enciende una alerta y suscita un amplio debate sobre los reales intereses del ESP y sus implicaciones a la educación del país. Esta discusión es fundamental para la construcción de un contrapunto más eficiente, basado en el esclarecimiento, en el protagonismo y en la lucha por una escuela más autónoma y democrática.

Palabras clave: Escuela Sin Partido. Control. Educación. Desposesión.

\section{Introdução}

A eficiência de regimes totalitários foi muito bem descrita por romances distópicos da primeira metade do século XX, a exemplo de Admirável mundo novo, escrito por Aldous Huxley em 1931, e 1984, de George Orwell, publicado pela primeira vez em 1949. A imposição de uma forma única de pensamento, o controle e a vigilância extrema, segundo Orwell (2009), seriam aperfeiçoados a ponto de pessoas doarem-se gratuitamente ao ato de vigiar. Antes de Orwell, Huxley (1979) havia advertido que a manipulação do Estado, lançando mão de eficientes métodos científicos, alcançaria o estágio em que as pessoas amariam sua própria servidão. O sentido de exploração do trabalho via cerceamento de liberdades nas mais variadas práticas profissionais também foi muito bem desenhado nessas obras.

Mas o futuro que elas anunciaram não está tão distante. Muito do que foi dito por Orwell encontra eco em projetos extremistas que se levantam em várias partes do mundo. O adensamento das formas de controle, ao beneficiar-se das estruturas organizacionais e do aparato tecnológico acumulados pelos Estados, vai tomando conta de diversos aspectos da vida cotidiana. O sistema educacional, nesse sentido, constitui-se como peça fundamental à cobiça cerceadora que visa, antes de tudo, impor uma forma única de pensamento e de educação. É nesse contexto que ganham evidência projetos como o Escola Sem Partido (ESP), que teve origem no Brasil em 2004. De início, a adesão foi pequena e muitos educadores subestimaram-no em razão dos absurdos e do anacronismo de muitas questões por ele apresentadas.

Com o tempo, especialmente com o avanço de mobilizações e movimentos conservadores, o ESP encontrou ressonância nas pautas neoliberais e, dez anos depois, o que parecia improvável para alguns ganha força também no plano jurídico, com a apresentação do primeiro 
projeto de lei à Câmara dos Deputados. Mas engana-se quem acredita que esta seja a via principal de ação dos idealizadores e apoiadores do ESP. Sua aparente isonomia (aparente porque o apartidarismo surge apenas no nome) começou a instigar polêmicas em torno das diretrizes educacionais em todo o país e muito do que tem sido suscitado por seus apoiadores termina por promover desvios de atenção dos reais problemas educacionais. Além disso, o que pode parecer malogro em função do arquivamento de projetos de lei do ESP em alguns estados e na Câmara dos Deputados, como ocorreu em 11 de dezembro de 2018, na realidade abriu caminho para a retomada de novas propostas com pontos ainda mais graves, como aconteceu no primeiro dia de trabalhos da Câmara dos Deputados em 2019, em que foi apresentado um novo projeto de lei, o PL no 246/2019 (Brasil, 2019).

O constante ataque a professores verificado nas redes sociais, na mídia e nas declarações de parlamentares e apoiadores do ESP também indica um dado que não pode ser subestimado. O professor tornou-se a figura a ser culpabilizada porque, apesar de todos os limites institucionais que acometem sua prática, o processo formativo de que ele participa tem como importantes premissas a autonomia e a liberdade de pensar. Isso significa que o ESP, ao contrário do que seus idealizadores costumam defender, vai compondo um movimento que, em essência, objetiva atacar frontalmente as liberdades e minar ainda mais a autonomia pedagógica.

Mas o ataque também é partidário. A escola e o sistema educacional vão se tornando uma arena de disputa entre partidos que pode confundir ainda mais as pautas da educação, desviando a atenção e acobertando articulações que buscam reduzir a função social da escola e torná-la um grande negócio. A conjugação dessas questões, somada ao incentivo à vigilância, à intimidação do trabalho docente e à difusão de concepções ultrapassadas e anacrônicas sobre educação, terminam por estimular um ambiente de formação ainda mais persuasivo, dual e limitado.

Situações de censura e de perseguição a professores relatadas e noticiadas em todo o país revelam o vínculo do ESP com tendências totalitárias e lembram muito bem as estratégias de controle descritas por Orwell (2009). Para muitos, a comparação com as distopias soa absurda. Mas, como afirma o famoso comediante estadunidense Mark Twain, falecido em 1910, "a verdade, às vezes, é mais estranha que a ficção, porque a ficção precisa fazer sentido e a verdade, não”. O ESP é justamente isso: 
sem sentido, estranho e carregado de contradições. O movimento não consegue esconder sua indiferença às liberdades. Mas as controvérsias, em muitos casos, também são intencionais porque ajudam a mascarar interesses maiores.

Neste texto analisamos estas questões e discutimos o vínculo do ESP com um projeto mais amplo de poder que aproveita do controle e da perseguição para tensionar o trabalho docente, desarticular o pensamento crítico e mascarar uma estratégia que visa fazer da educação um grande negócio via espoliação. Analisar essas questões e o modo como podem desencadear processos mais amplos de desmontes na educação é fundamental para a construção de um contraponto mais eficiente, baseado no diálogo, no esclarecimento, no protagonismo e na luta pela autonomia pedagógica e pela escola que queremos.

\section{A história de um projeto}

A história de um projeto como o ESP não é produto do acaso ou de uma ideia isolada. Por isso, é preciso entender o contexto social e as circunstâncias que influenciaram o seu surgimento e sua ressonância com projetos maiores. A primeira proposta do ESP foi elaborada em 2004 pelo advogado Miguel Nagib (ESP, [2018?]). Mas foi dez anos depois, em função do amplo apoio de parlamentares e empresários, motivados por crescentes mobilizações conservadoras, que o texto idealizado por Nagib deu origem a vários projetos de lei. O primeiro deles, o PL n ${ }^{0}$ 7.180/2014, foi apresentado à Câmara dos Deputados em 24 de fevereiro de 2014 pelo deputado Erivelton Santana, na época filiado ao PSC da Bahia.

No site do ESP há textos de anteprojetos de lei disponíveis para download e replicação nas esferas municipal, estadual e federal (ESP, [2018?]). O projeto foi apresentado em Assembleias Legislativas do Rio de Janeiro, de Goiás, São Paulo, Espírito Santo, Ceará, Distrito Federal, Rio Grande do Sul e Alagoas, bem como em dez Câmaras de Vereadores (São Paulo-SP, Rio de Janeiro-RJ, Curitiba-PR, Palmas-TO, Joinville-SC, Santa Cruz do Monte Castelo-PR, Toledo-PR, Vitória da Conquista-BA, Cachoeira do Itapemirim-ES e Foz do Iguaçu-PR).

Alagoas chama a atenção por ter sido o primeiro estado a aprovar uma lei inspirada no ESP. Intitulada "Escola Livre", essa lei aguarda votação no Supremo Tribunal Federal (STF) por ter sido questionada por 
Ação Direta de Inconstitucionalidade (ADI). Mas há também estados que se mobilizaram contra o ESP. É o caso da Paraíba, que aprovou, em 4 de dezembro de 2018, o PL $\mathrm{n}^{\circ} 2.013 / 2018$, o qual garante a liberdade de expressão, de pensamentos e opiniões nas redes pública e privada do estado. Na Câmara dos Deputados, em oposição ao ESP, foi apresentado o Projeto de Lei “Escola Sem Mordaça” (PL nº 502/2019) em 6 de fevereiro de 2019, pela deputada Talíria Petrone (PSOL-RJ).

Antes disso, o projeto de lei do ESP havia sido arquivado em comissão da Câmara dos Deputados no dia 11 de dezembro de 2018. Contudo, a comemoração precipitada de algumas pessoas contrárias ao projeto deixou de considerar a grande possibilidade de seu desarquivamento e o fato da proposta encontrar um "ambiente" parlamentar ainda mais favorável com a posse de Jair Bolsonaro. Não demorou e em menos de dois meses um novo projeto, o PL no 246/2019 (Brasil, 2019), com pontos ainda mais graves, foi apresentado pela deputada Bia Kicis (PSL-DF). Isso ocorreu em 4 de fevereiro, primeiro dia de trabalhos da Câmara dos Deputados no ano.

Além de conter o antigo texto do ESP, o novo projeto, em seus artigos $7^{\circ}$ e $8^{\circ}$, visa regular as atividades dos grêmios estudantis e garantir o direito aos alunos de gravarem as aulas. No primeiro caso, há uma tentativa explícita de intervenção na forma de organização dos estudantes e de impedimento de suas mobilizações. No segundo caso, a intimidação ao professor via recursos tecnológicos é evidente, além do incentivo à vigilância e censura ao trabalho docente e à liberdade de cátedra, o que fere princípios constitucionais.

Em geral, a principal justificativa dos projetos de lei do ESP é a de que haveria doutrinação ideológica de esquerda nas escolas brasileiras. Conforme consta do PL n ${ }^{\circ}$ 246/2019, é necessário adotar medidas eficazes para prevenir "práticas de doutrinação política e ideológica nas escolas e a usurpação do direito dos pais a que seus filhos recebam a educação moral que esteja de acordo com suas próprias convicções” (Brasil, 2019). Ao longo deste texto, evidenciaremos contradições desse projeto e o modo como seus idealizadores interpretam de maneira isolada e descontextualizada um dispositivo da Convenção Americana sobre Direitos Humanos. A preocupação com o que chamam de doutrinação ideológica levou o deputado Rogério Marinho (PSDB-RN) a apresentar o PL nº 1.411/2015, que tipifica o crime de "assédio ideológico" nas escolas. O projeto foi retirado por seu próprio autor. Segundo ele, o objetivo, "foi cumprido ao provocar o 
debate e combater doutrinadores que insistem em agredir diuturnamente crianças brasileiras e deseducá-las” (Brasil, 2017).

Apesar do grande esforço em torno dos projetos de lei, a história do ESP não se encerra no plano jurídico. Pelo contrário. O estímulo à intimidação de professores transformou-se em uma campanha aberta de adeptos do movimento, até mesmo de parlamentares. Caso emblemático foi o da deputada eleita pelo PSL de Santa Catarina, Ana Caroline Campognolo, que fez um chamado público, via redes sociais, para que os alunos gravassem e denunciassem seus professores (Deputada..., 2018). O Ministério Público estadual solicitou a retirada da publicação feita pela deputada, que recorreu à Justiça de Santa Catarina e conseguiu liminar em 24 de janeiro de 2019 permitindo a divulgação de seu chamado. A liminar, no entanto, foi derrubada pelo STF em 8 de fevereiro de 2019.

Nota-se que, embora o ESP viole princípios constitucionais como a liberdade de expressão da atividade intelectual e o direito ao pluralismo de ideias, a arena jurídica parece não conter a onda de censura. Ao induzir alunos e familiares a vigiarem e intimidarem professores, o movimento demonstra sua característica torpe e seu descompromisso com princípios pedagógicos e constitucionais. Alegando haver doutrinação esquerdista nas escolas, o movimento também termina por dicotomizar o ambiente de aprendizado, evidenciando sua postura partidária, a tentativa de eliminação de tudo o que diverge de suas posições e uma concepção bastante ultrapassada do processo ensino-aprendizagem quando trata o estudante como algo manipulável. Sua obsessão por vigilância e controle, portanto, guarda relação com um entendimento específico do processo ensino-aprendizagem.

\section{Perseguição, controle e a visão ultrapassada do processo ensino-aprendizagem}

Quando a obediência é consentida e o ato de vigiar passa a ser exercido de maneira voluntária, isso significa que o controle e o cerceamento atingiram um estágio avançado de eficiência. Mas em que situação isso é possível? Em que tipo de regime político e institucional as formas de controle podem alcançar essa eficiência? Como fica o processo formativo em circunstâncias que coíbem a autonomia e a liberdade de pensar e divergir? 
Quando o ESP incentiva os estudantes a monitorarem as aulas e a rotina do professor, em realidade está distanciando o processo formativo de sua autenticidade. $\mathrm{O}$ incentivo à intimidação, além de evidenciar o viés totalitário do movimento, também demonstra uma visão ultrapassada de seus idealizadores em relação ao processo ensino-aprendizagem. Como pensar nesse processo tendo o professor como um ser vigiado? A utilização de tecnologias para monitorar a aula traz um elemento atordoador não somente à atividade docente, mas também ao estudante. Em vez de ter a sua atenção voltada à interação e à interpretação, o aluno concentra-se no ato de vigiar.

Além de mudar o foco e reduzir o aprendizado, a condição de sentinela e de cagoete embrutece o espírito investigativo, diminui a visão de mundo e dicotomiza o saber. O conhecimento fica reduzido a duas partes: àquela que o estudante pensa ser a correta e àquela que deve ser vigiada, impedida e denunciada. Além desse dualismo, o ESP, por um lado, subestima o aluno ao concebê-lo como doutrinável e vulnerável e, por outro, trata o professor como mero transmissor de conteúdo. A concepção de ensino baseada na lógica formal tem o objetivo implícito de restringir o ensino ao modelo tecnicista. Mas esse modelo é direcionado principalmente aos filhos de trabalhadores, tidos como sujeitos que devem obedecer.

Fato é que, ao mesmo tempo que o docente é reduzido a transmissor de conteúdo, ele também é superestimado ao ser concebido como alguém que manipula os alunos e impõe seu conhecimento. Há, portanto, uma estigmatização do professor como doutrinador e uma redução dos alunos a vulneráveis e/ou meros receptadores de conteúdos. Os filtros cognitivos dos estudantes e sua autonomia de pensar e de produzir conhecimento via processos interativos, além da diversidade que compõe o universo docente, são desconsiderados. Isso expõe o desconhecimento e/ou a negligência por parte dos idealizadores e apoiadores do ESP acerca de teorias da aprendizagem.

A mediação cumpre papel fundamental na aprendizagem escolar. A construção e ampliação de saberes, "o confronto de diferentes tipos de conhecimentos, o desenvolvimento de capacidades cognitivas do pensamento abstrato", conforme assinala Cavalcanti (1998, p. 12), "são processos que podem ser potencializados com práticas de intervenção pedagógica”. O conhecimento escolar, complementa a autora, constrói-se 
no confronto entre conceitos cotidianos e conceitos científicos. É por isso que o ensino, ao promover o encontro desses tipos de conhecimento, torna indispensável a mediação do professor. Isso significa, como ensina Vygotsky (1984), que a aprendizagem mediada demanda organização e processos interativos. Ao contrário da lógica formal, que considera a obtenção de conhecimento como um processo automático, na perspectiva sociocultural o estudante constrói suas próprias ideias a partir do que foi trabalhado e das interações desenvolvidas com os colegas.

Isso mostra a importância das atividades conjuntas e colaborativas. Por isso, em vez de incentivar práticas cerceadoras e punitivas em sala de aula, é muito mais sensato e produtivo estimular a colaboração e o apoio mútuos, como defende Kropotkin (2014). Criar condições e ampliar os espaços de interação e de sociabilização nas práticas pedagógicas pode favorecer o crescimento intelectual e o desenvolvimento cognitivo dos estudantes. Ao articular os conhecimentos adquiridos no dia a dia com aqueles aprendidos na escola, o estudante vai desenvolvendo sua consciência de mundo, dos processos históricos, da complexa realidade e de suas contradições. O ensino mais contextual, baseado na livre pesquisa conjunta e na correlação entre os conceitos trabalhados pelo professor e aquilo que se vivencia no cotidiano, são elementos fundamentais do aprendizado, como salienta Boneta i Carrera (2017) em interessante trabalho sobre as experiências pedagógicas do grande educador catalão Artur Martorell. Por meio da mediação também é fundamental ajudar as crianças a despertar o desejo de conhecer e compreender os fenômenos da vida. A imaginação, nesse sentido, tem um papel fundamental na construção do raciocínio científico, argumenta Kropotkin (2014). É em meio a esse processo, portanto, que os estudantes vão construindo sua própria forma de pensar e agir no mundo.

Portanto, mesmo que um professor tenha muito bem definida sua concepção política, isso não significa que os estudantes irão segui-la. Pode ser normal haver um professor que seja assíduo leitor e adepto de autores conservadores, mas também pode haver estudantes que se contraponham ao docente por defender posições diferentes. Não há problema nisso. Apesar de ser um ator fundamental no processo ensino-aprendizagem, o educador não tem o poder de que tanto se queixa o ESP. Seja o professor de esquerda, de direita, de centro, autonomista ou de qualquer outra tendência política, o seu interesse deve orientar-se para que o estudante 
tenha plenas condições de construir sua autonomia, de pensar por si próprio e ter sua visão de mundo para que tenha condições de questionar, concordar ou discordar do professor.

\section{A falsa premissa de neutralidade}

A neutralidade e o apartidarismo são premissas bastante enfatizadas pelo ESP. Mas como isso é possível se o próprio movimento é apoiado e patrocinado por partidos como PSL, PSC e DEM? A pauta conservadora bastante defendida pelo projeto não é novidade. Não restam dúvidas sobre que tipo de escola e de formação o movimento prega. A defesa de determinada pauta é um direito, mas, quando essa defesa é acompanhada de perseguição a outras pautas, trata-se de totalitarismo.

Além disso, ao difundir a crença de que as escolas foram tomadas pelo marxismo e por um exército de "doutrinadores esquerdistas", o ESP contribui com a formação de uma opinião equivocada do trabalho docente e da realidade das escolas brasileiras. Esses estereótipos geralmente partem de pessoas muito alheias ao espaço escolar. Nas vésperas de sua posse, o próprio presidente disse que "o lixo marxista se instalou nas escolas" (UOL, 2018). Ao dizer isso, Bolsonaro demonstra total desconhecimento tanto do autor como das escolas brasileiras. Conforme pontuamos, se a obra de Marx é abordada de maneira bastante elementar até mesmo em disciplinas de economia política, imagine nas escolas? (Castilho, 2019). Os livros I, II e III de $O$ capital, publicados pela Editora Boitempo em 2011, 2014 e 2017, respectivamente, somam 2.638 páginas. O livro IV, publicado pela Editora Difel, está dividido em três volumes que somam 1.616 páginas. Juntos, os quatro livros agregam 4.254 páginas. Se é difícil encontrar um professor que tenha realmente lido essa obra (note-se que ela não resume o marxismo), é simples concluir até onde foi o exagero e a detração do presidente.

No que tange à queixa de que um exército de doutrinadores esquerdistas tenha dominado as escolas brasileiras, é necessário entender alguns números. Como mostra a Figura 1, o Brasil possui 181.939 escolas de educação básica. Destas, 60,6\% são municipais, 22,3\% privadas, $16,7 \%$ estaduais e $0,4 \%$ federais. Trabalham nessas escolas 2,2 milhões de docentes, $60,9 \%$ dos quais atuam no ensino fundamental, segundo o Instituto Nacional de Estudos e Pesquisas Educacionais Anísio Teixeira (Inep, 2019). Conforme destaca Ratier (2016), até o momento, os dados sobre filiação de professores da educação básica a partidos políticos não confirmam a queixa do ESP. Ratier acrescenta ainda que os levantamentos 
realizados pelo Instituto Brasileiro de Geografia e Estatística, indicam que apenas $10 \%$ dos professores dizem ser filiados a partidos. Os dados mais atuais do Tribunal Superior Eleitoral (TSE) sobre filiação partidária da população brasileira, de acordo com Ratier (2016), mostram que o partido com maior número de filiações é o MDB, com 10,3\% do total nacional. Este e o PSDB somam, juntos, 24,5\%.

Figura 1 - Número de estabelecimentos de ensino e de docentes da educação básica - Brasil, 2018

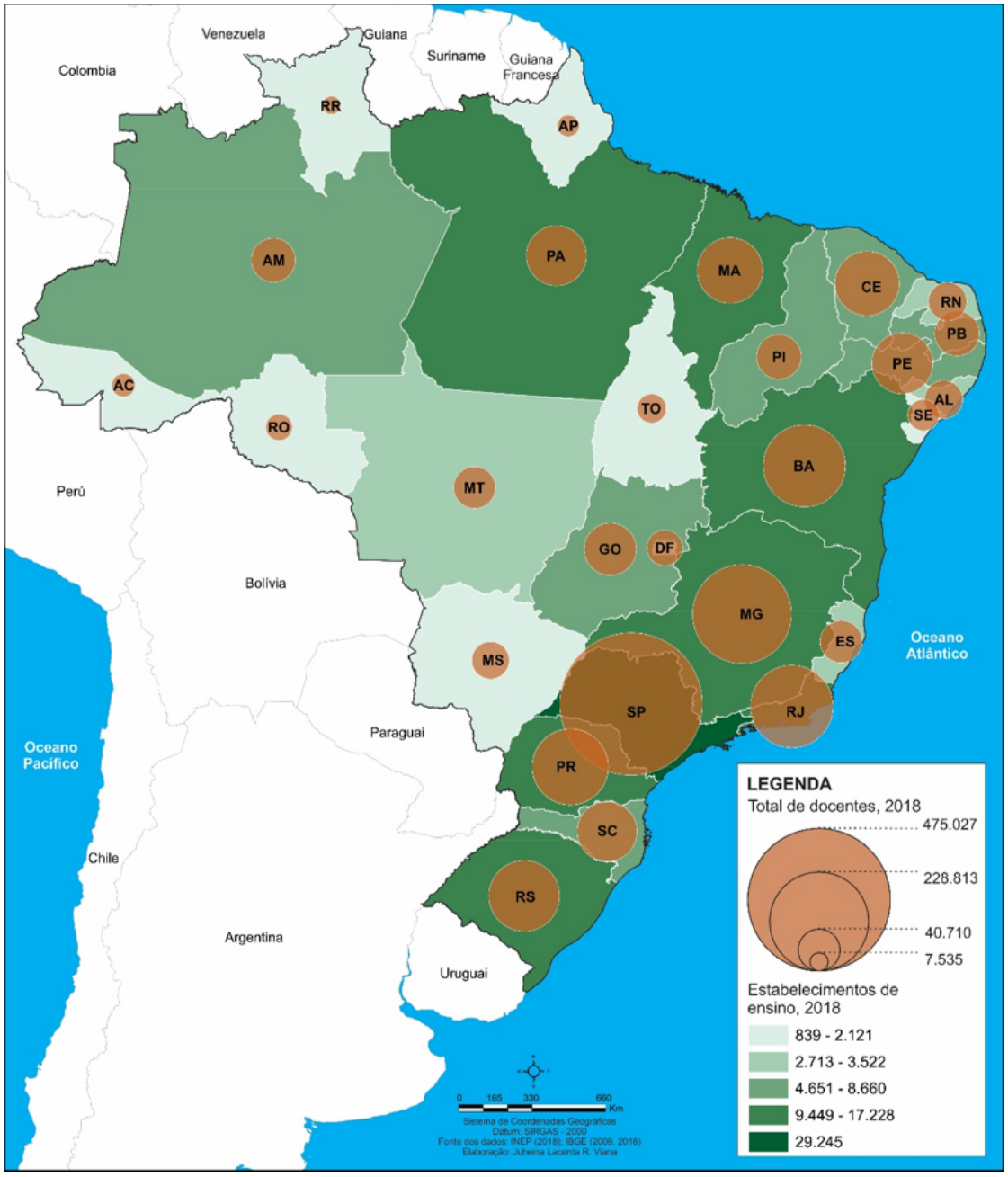

Fonte: Inep (2019). 
Não é novidade que o percentual de filiações a partidos mais conservadores seja superior àquele de partidos de esquerda. Também não é de estranhar que esse universo traduz uma escola muito mais conservadora do que qualquer outra coisa. Ao mesmo tempo, é indiscutível que haja uma grande diversidade de posições políticas entre professores das redes de ensino de qualquer município ou região do país. Essa diversidade, aliás, não é um problema. Apenas evidencia que a escola não está separada da sociedade onde se insere. Não sendo uma ilha, o espaço escolar traduz a diversidade, os problemas e as contradições da realidade em que está inserido. Como afirmamos em texto anterior, a formação que leva à militância (e vice-versa) geralmente acontece nos espaços de mobilizações e nos movimentos sociais, e não, necessariamente, em sala de aula (Castilho, 2018). O contato de estudantes com uma literatura mais crítica e revolucionária geralmente ocorre em espaços e redes de militância, no diálogo com companheiros de mobilização, em cursos de curta duração, em encontros, assembleias, organizações de base etc.

Isso significa que a formação política transcende a sala de aula. Mesmo que haja um professor ou aluno que não seja filiado a algum partido político e mesmo que eles discordem dos princípios defendidos por qualquer sigla partidária, esse posicionamento não deixa de ser político. É por isso que a neutralidade partidária do ESP é uma falácia. Além do vínculo com partidos conservadores, o movimento não deixa dúvida quanto à sua visão de mundo e à absoluta intolerância com o pensamento crítico e autônomo. É por isso que o projeto também ficou conhecido como "Escola da Mordaça” ou "Escola do Pensamento Único".

Os ideólogos do ESP também utilizam, com frequência, um dispositivo da Convenção Americana sobre Direitos Humanos para justificar a coibição de certos temas. O Artigo 12 do dispositivo expressa o seguinte: "os pais [...] têm direito a que seus filhos ou pupilos recebam a educação religiosa e moral que esteja acorde com suas próprias convicções”. Esse dispositivo, como observa Ximenes (2016, p. 55), "não pode ser lido de forma descontextualizada e isolada como tem feito o ESP, mas enquanto parte do direito à educação em sentido amplo”. O direito dos pais no âmbito da educação informal (que se estabelece no ambiente familiar e ao longo da vida) e não formal (que diz respeito às iniciativas de formação que acontecem fora dos sistemas de ensino) "não é incompatível com o tratamento de questões morais, políticas e sexuais na educação formal”. 
Ximenes (2016, p. 55) ainda acrescenta que a inclusão de tais temas nos conteúdos escolares "é parte do direito dos estudantes de ver ampliados os seus referenciais a partir de concepções diversas, republicanas e científicas, todas necessárias ao pleno exercício da autonomia”. É por isso que, ao coibir conteúdos que julgam estar em conflito com as convicções morais da família, o ESP está subvertendo o sentido do referido dispositivo. A exclusão de certos conteúdos também pode incorrer na conivência com problemas como racismo, machismo, misoginia e homofobia.

Longe de admitir o pluralismo de ideias, o ESP concebe um padrão único de família e de religião, veste-se de moralidade, mas guarda indiferença com importantes conquistas no que diz respeito aos direitos humanos e à diversidade cultural. Negar essa diversidade e o trabalho em torno de sua valorização é negar a própria escola. Isso fere um princípio fundamental do Artigo $3^{\circ}$ da Constituição Federal (Brasil, 1988), que pontua como importante objetivo do Estado democrático de direito "promover o bem de todos, sem preconceitos de origem, raça, sexo, cor, idade e quaisquer outras formas de discriminação".

\section{A criminalização do professor, o mercado escolar e a mira na espoliação}

Levantamento realizado pelo Ministério da Educação (MEC) mostra que menos da metade dos municípios brasileiros (45\%) pagam salário equivalente ao piso nacional $(\mathrm{G} 1,2017)$. Isso significa que 3.037 municípios não pagam o piso aos seus professores. O baixo salário dos docentes, aliado aos problemas infraestruturais das escolas e às más condições de trabalho, ajudam a explicar o alto número de analfabetos funcionais, que atinge $30 \%$ dos brasileiros entre 5 e 64 anos. A taxa de analfabetismo absoluto, calculada pelo IBGE ([2018]), manteve-se na faixa de 7\%, ou 11,5 milhões de pessoas com 15 anos de idade ou mais. Esse índice é ainda mais alto em estados das regiões Norte e Nordeste. O Censo da Educação Básica de 2018 também revela que diversos municípios dessas regiões não possuem bibliotecas ou salas de leitura em $80 \%$ de suas escolas (Figura 2). 
Figura 2 - Percentual de escolas por município que possuem bibliotecas - Brasil, 2018

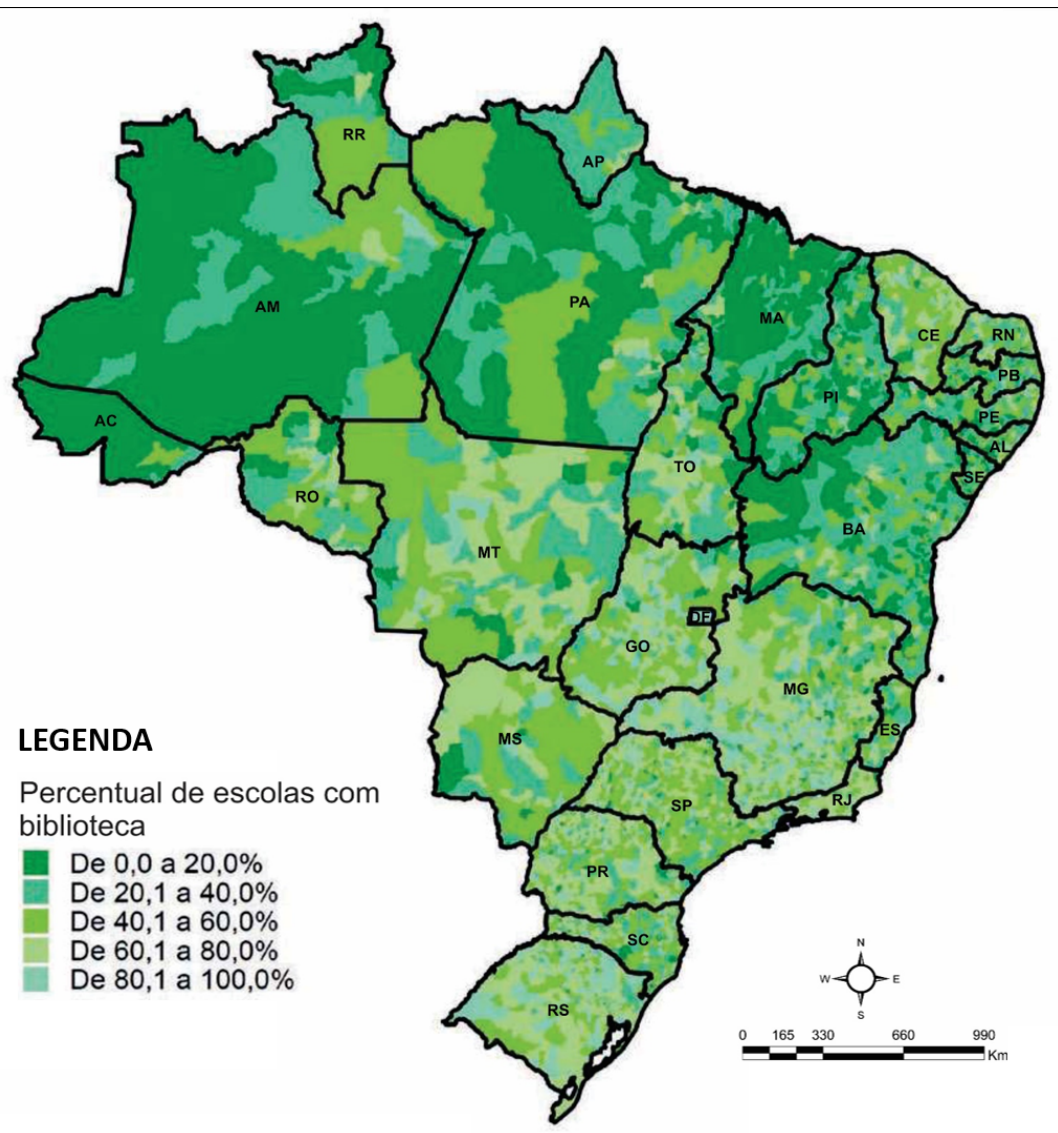

Fonte: Inep (2019).

Conforme mostra a Figura 3, apenas 30,2\% das escolas municipais de educação infantil do país possuem biblioteca. No ensino fundamental e médio os valores são, respectivamente, de 40,1\% e 80,3\% (Figura 4). Impressiona o fato de apenas $31 \%$ das escolas municipais com oferta de creche possuírem berçário. É também muito baixo o percentual de escolas com banheiros adequados à educação infantil $(38,1 \%)$ e área verde $(27 \%)$. 
Figura 3 - Percentual de escolas de educação infantil que possuem biblioteca e outros recursos Brasil, 2014 a 2018

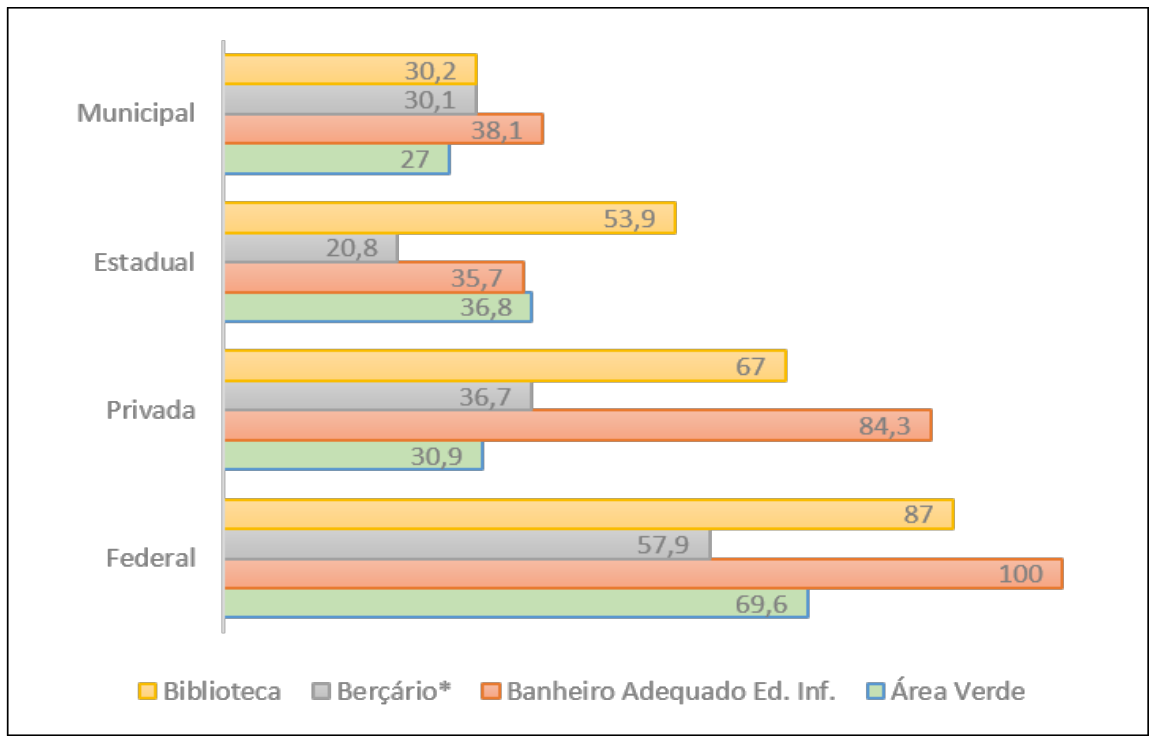

Nota: Dados trabalhados pelo autor.

${ }^{*}$ Os percentuais consideram apenas as escolas com oferta de creche.

Fonte: Inep (2019).

As instituições federais possuem laboratório de ciências em 95\% das escolas do ensino fundamental e em $83,4 \%$ das escolas do ensino médio. Todavia, essas instituições representam apenas 0,8\% das matrículas da educação básica no país. Nas redes municipais, que somam $47,7 \%$ das matrículas, apenas 3,4\% das escolas do ensino fundamental e $28,8 \%$ do ensino médio têm laboratório de ciências. Nas escolas estaduais, essa estrutura aparece em apenas $24,4 \%$ das escolas do ensino fundamental e $37,5 \%$ do ensino médio (Figura 4). 
Figura 4 - Percentual de escolas do ensino fundamental e médio que possuem biblioteca e outros recursos - Brasil, 2018

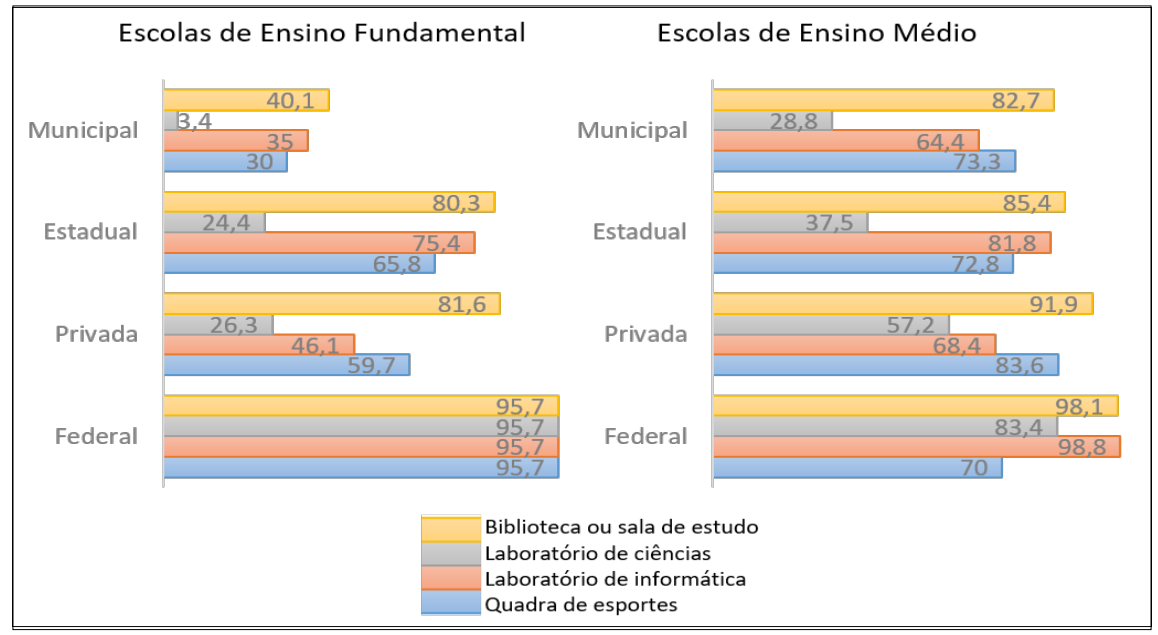

Nota: Dados trabalhados pelo autor.

Fonte: Inep (2019).

Esses dados, no entanto, não sensibilizam os idealizadores do ESP. Enquanto centenas de escolas mal possuem carteiras, a campanha desse movimento é de incentivo ao monitoramento e à censura ao trabalho docente. Acreditar na sensibilização do ESP perante os reais problemas das escolas brasileiras seria ingenuidade. Sua intenção maior, "além de dissimular os reais desafios da educação, é voltada ao controle e imposição de um pensamento único e acaba indo ao encontro de projetos que intentam cooptar o sistema público de ensino e torná-lo um grande negócio" (Castilho, 2018). Reformas como a do ensino médio e a homologação de diretrizes autorizando que 30\% dessa etapa escolar seja realizada a distância, além da proposta de implantação de Organizações Sociais (OSs) nas escolas, evidenciam articulações nesse sentido e abrem caminho para um tipo de apropriação das redes de ensino por parte de grandes grupos empresariais que culmina no que Harvey (2005) denomina “acumulação por espoliação".

Essa forma de apropriação intenta, sobretudo, obter acesso à significativa parcela de recursos públicos para a sua reprodução. Em 2018, por exemplo, conforme dados do Portal da Transparência da 
Controladoria-Geral da União (2018), foram destinados R $\$ 15,3$ bilhões à educação básica. Embora o investimento brasileiro por aluno seja baixo, conforme explicaremos mais adiante, a descapitalização do sistema público não deixa de ser uma condição para a capitalização pública do mercado privado, como bem observa Arrais (2016). O montante destinado à educação básica, nesse sentido, é muito cobiçado pelos grupos empresariais porque os contratos firmados com o Estado, além de garantirem lucro fácil, possibilitam outras formas de captação. Somam-se a isso a oferta de cursos a distância (com sérios prejuízos à formação dos estudantes) e a contratação de terceirizados (o que amplia ainda mais a precarização do trabalho).

Kropotkin (2009) já falava de espoliação no final do século XIX e início do XX, quando observou relações de opressão e de espoliação oriundas de um poder consubstanciado no Estado. Atualmente a espoliação permite liberar ativos para serem lucrativamente apropriados por excedentes de capital. É por isso que Harvey (2005) destaca que o acesso ao sistema financeiro é um trampolim de predação, fraude e roubo. O grande interesse de apropriação privada dos sistemas de ensino também guarda relação com a obsessão por uma formação técnica direcionada a grande parte dos estudantes, especialmente aos filhos de trabalhadores. É por isso que o currículo também se torna uma arena de disputa entre setores mais conservadores e setores de esquerda, o que reforça ainda mais o papel da escola como aparelho de Estado dominante (Althusser, 1980). Essa disputa, que também se torna uma disputa partidária, tumultua sobremaneira o debate sobre os destinos da educação do país, desvia a atenção de seus reais problemas e deixa a escola ainda mais distante de sua autonomia.

É ainda mais grave quando apoiadores do ESP responsabilizam os professores por um suposto fracasso da formação escolar, uma vez que terminam por acobertar sérios problemas das escolas e por inflamar ainda mais a pauta do sistema educacional. Isso acende um alerta porque não deixa de direcionar esforços a dilemas enganosos. Responsabilizar um profissional que já carrega um fardo desproporcional em virtude de seu baixo salário e das difíceis condições de trabalho tende a piorar ainda mais as relações no ambiente escolar.

Uma professora de 38 anos do Distrito Federal, em entrevista ao jornal Correio Brasiliense em novembro de 2018 (Oliveto, 2018), relata 
que, apesar da lida com a rebeldia de estudantes, jamais pensou que seu comportamento poderia ser afetado a ponto de adoecer. Segundo ela, sofre ameaças e constrangimentos e os alunos apontam o celular em sua direção durante as aulas. Além disso, recebeu mensagem, via rede social, dizendo que seria torturada por "ideologia de gênero". A professora acrescenta que nunca concordou com espécie alguma de doutrinação porque a escola é, ou deveria ser, um ambiente de livre debate. No entanto, depois de "dar uma aula sobre direitos civis, sobre voto feminino e ser acusada de ideologia de gênero, uma coisa que nem existe”, o que pensa é deixar a profissão (Oliveto, 2018).

Há um temor por parte de professores, especialmente da rede privada, em enfrentar processos. Isso tem causado uma espécie de autocensura. Apesar de muitos processos contra professores não seguirem adiante, relatos evidenciam que a censura, o constrangimento e a perseguição têm sido cada vez mais comuns em escolas de todo o país. ${ }^{1}$ Em alguns casos, o constrangimento vem do próprio colega ou do corpo gestor, lembrando muito as distopias apresentadas no início deste texto quando se referem à vigilância exercida de maneira voluntária por aqueles que, em essência, são afetados por ela.

A responsabilização e o incentivo à censura do professor apenas adensam relações de ódio e de vigilância. Em seu site, o ESP chega a considerar professor e aluno como competidores (ESP, [2018?]). Não é difícil encontrar declarações de seus apoiadores referindo-se ao professor como "abusador", "agressor", "doutrinador", "deseducador de crianças". A ideia que difundem, neste caso, é a do professor como uma espécie de adversário do aluno e inimigo da educação. Não resta dúvida de que esse ataque faz parte da estratégia do ESP de disputa por hegemonia sobre a escola e de arrefecimento de qualquer perspectiva que caminhe em outra direção.

É certo que a responsabilização do professor apenas piora a situação. Mas uma das intenções implícitas do ESP é justamente inflar o debate escolar e desviar a atenção de demandas populares, como as políticas de investimentos em educação pública. É por isso, por exemplo, que milhares de escolas sem condições mínimas de trabalho e de aprendizagem não sensibilizam o movimento ESP. A preocupação com investimentos virá desse movimento somente quando grupos empresariais tiverem acesso, via espoliação, aos recursos da educação. Pouco se importam com o baixo 
salário dos professores (que, aliás, poderá piorar com as terceirizações), com as péssimas condições de trabalho em grande parte das escolas e com os recentes cortes de investimentos destinados à educação.

Dados da Secretaria do Tesouro Nacional revelam que, entre 2013 e 2018, houve queda de 66\% dos investimentos em educação (DCI, 2018). Um dado muito preocupante diz respeito à quantidade de crianças brasileiras de 0 a 5 anos que não frequentam a escola. De acordo com o IBGE ([2018]), em 2017 eram 7,3 milhões de crianças nessa condição. Havia 196 mil crianças entre 4 e 5 anos de idade sem frequentar a escola por falta de vaga ou inexistência de escola na sua localidade de residência (Figura 5). Um estudo realizado pela Organização para a Cooperação e Desenvolvimento Econômico (OCDE) revela que o Brasil investe anualmente 3,8 mil dólares por aluno da educação básica, muito abaixo da média dos demais paísesmembros, que é de 8,7 mil na fase que vai até a quinta série e de 10,5 mil no restante dos anos do ensino fundamental e médio (OCDE, 2018).

Figura 5 - Motivos pelos quais crianças de 4 a 5 anos de idade não frequentam a escola - Brasil, $2018(\%)$

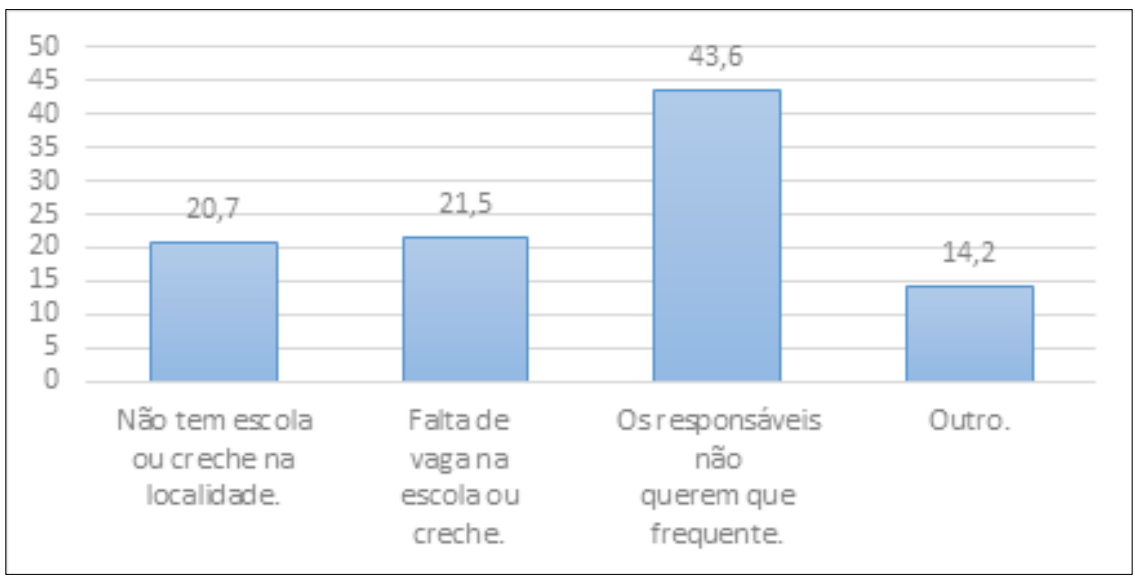

Nota: Dados trabalhados pelo autor.

Fonte: IBGE, [2018].

Esse baixo investimento também reflete nas condições de trabalho dos professores, especialmente das escolas públicas. O desestímulo à 
carreira docente no Brasil pode repercutir negativamente na procura por cursos de licenciatura e na qualidade da formação docente. Um estudo realizado em 35 países intitulado Global Teacher Status Index 2018 (Índice Global do Status do Professor), mostra que o Brasil é aquele que menos valoriza professores (Dolton et al., 2018).

Mais uma vez, esses dados não sensibilizam o ESP, bastando citar sua campanha implícita de criminalização de professores. A querela do movimento em torno do trabalho docente merece ser debatida e desmascarada. Mas o debate em torno dos problemas educacionais não pode ser reduzido às pautas do ESP porque, por trás da campanha de censura e de criminalização do professor, há um projeto mais amplo que visa tornar a educação um grande negócio, direcionar um ensino tecnicista e mais reduzido (com parte da carga horária realizada a distância) a determinados estudantes, especialmente filhos de trabalhadores, e impor um conjunto de medidas que objetivam minar a autonomia pedagógica e ampliar o controle sobre a escola. Isso explica o incentivo à vigilância e à perseguição ao educador. A crítica a esse movimento, no entanto, não pode ser feita de maneira isolada. Há uma luta que antecede esse debate e que é mais ampla: ela diz respeito ao tipo de escola que desejamos construir.

\section{Para não terminar: que escola queremos?}

Há uma relação implícita entre o ESP e um projeto mais amplo de poder. A leitura atenta dessa relação e o seu enfrentamento são fundamentais, mas este não pode ser feito sem se ter clareza sobre que tipo de escola queremos. A crítica ao ESP, nesse sentido, não é seguida de um conformismo com a escola que temos, mesmo porque o excesso de controle - tanto do currículo como dos processos formativos - não nasceu neste século. A questão, obviamente, é que o ESP defende formas de controle ainda mais extremas e com signos de perseguição que já se manifestam em várias escolas do país.

É por isso que o momento exige cautela, muito diálogo, conscientização e construção coletiva de alternativas. A leitura atenta das reais intenções do ESP é fundamental para evitar esforços em direções erradas, porque a maioria das questões suscitadas pelo movimento não passam de quimeras divulgadas intencionalmente para desviar a atenção e acobertar interesses maiores. Por isso, os problemas da educação devem 
ser pautados sobretudo pelos trabalhadores que vivenciam e conhecem, de fato, a realidade escolar. O protagonismo desses sujeitos é de suma importância, mas também há o desafio de construirmos pontes, vínculos mais efetivos e aproximações que possibilitam o diálogo, a junção de forças e de ações por uma escola mais autônoma.

Esse desafio também deve ser dos trabalhadores e estudantes de outras instituições, como as universidades, porque a distância que ainda os separa da vida escolar, salvo raras exceções, precisa ser encurtada de modo que a retórica dê lugar à união e ao enfrentamento. Somente pautando e aproximando-se da escola real, com seus dramas e desafios, será possível defendê-la das ofensivas neoliberais e potencializá-la na direção da autonomia. Por outro lado, se canais de diálogo não forem construídos e se não formos capazes de lutarmos pela escola que queremos, a inércia abrirá campo para uma escola ainda mais autoritária, vigiada e punitiva.

Na escala mais imediata, é fundamental que os professores assumam mais sua profissão, porque a luta e defesa do trabalho docente não pode ser feita por um espírito desacreditado. Dados do IBGE ([2018]) mostram que um professor no Brasil recebe até 39\% menos que profissionais com escolaridade similar. Somam-se a isso as más condições de trabalho e a perseguição à sua liberdade de cátedra. A construção de um outro sentido de valorização desse trabalhador, no entanto, não virá de cima para baixo. Ela deve ser conquistada e exige da própria categoria docente mais envolvimento, protagonismo e luta em defesa dessa profissão.

Ainda na escala imediata, as demandas básicas da educação devem ser defendidas com muito empenho por aqueles que realmente têm compromisso com um ensino público e de qualidade. Dentre essas demandas, destaco três: 1) escolas com infraestrutura adequada ao pleno aprendizado; 2) melhores salários aos professores e condições de trabalho que lhes permitam desenvolver a sua prática, respeitando-se as especificidades de cada conhecimento; 3) garantia irredutível da autonomia pedagógica do professor (independentemente de sua posição política e ideológica) e do aprendizado dos estudantes (Castilho, 2018). A defesa desses pontos é fundamental, pois conjuga um desafio maior e que diz respeito à autonomia da escola. Cada vitória sobre qualquer restrição às liberdades significará um passo adiante na luta por uma escola mais autônoma. 
Nessa luta, é indispensável o envolvimento efetivo de professores, estudantes e funcionários na organização e nas rotinas da escola. Esse protagonismo, aliado à livre pesquisa, ampliará o acesso ao aprendizado e ao desenvolvimento do raciocínio científico. Sem liberdade, interação, mediação e estímulo à imaginação, o processo de produção de conhecimentos torna-se limitado. Por isso, é imprescindível que a escola seja um lugar onde se incentivam valores universais como a colaboração, a solidariedade e o respeito às diferenças. Isso possibilita construir novos sentidos de vivências de modo que a competição, a censura e a perseguição sejam substituídas pela cooperação e pelo apoio mútuo, em um processo em que todos os envolvidos crescem juntos.

Sem nunca abrir mão da ciência e da liberdade, nós é que devemos problematizar esses desafios e lutar pela escola que desejamos. Ela não deixará de ser um lugar de disputa, obviamente. No entanto, ao contrário do que prega o ESP, a disputa não é feita apenas por dois lados. A vida, a política e o conhecimento são bem mais amplos, desafiadores e diversos. É por isso que a escola nunca será território de um pensamento único. Ela traduz o movimento do mundo, a diversidade da sociedade e suas contradições. Por isso, se ela é motivo de disputa, também pode ser um lugar de luta - afinal, os tempos podem ser de controle e de perseguição, mas os espaços nunca deixarão de ser instâncias de dissidências e de devir.

\section{Notas}

1 Relatos de perseguição a professores, afastamento ilegal, intimidação etc. têm surgido em todo o país. Diante disso, um conjunto de iniciativas organizadas por diversas entidades e pelo Ministério Público Federal, a exemplo da publicação do Manual de defesa contra a censura nas escolas (2018), tem sido desenvolvido no sentido de fornecer informações jurídicas e esclarecimentos aos professores para que saibam se defender.

\section{Referências}

ALTHUSSER, Louis. Ideologia e aparelhos ideológicos de Estado. Tradução de Joaquim José Moura Ramos. 3. ed. Lisboa: Editorial Presença; São Paulo: Martins Fontes, 1980.

ARRAIS, Tadeu A. O Grand Tour da educação goiana: capitalização pública do sistema privado via Organizações Sociais. Territorial - Caderno Eletrônico de Textos, v. 6, n. 8, 1 fev. 2016. 
BONETA I CARRERA, Martí. Llums a la Vall Fosca. Memòries d'Artur Martorell de les colònies escolars a Capdella (1917 i 1918). Tremp: Garsineu Edicions, 2017.

BRASIL. Câmara dos Deputados. Constituição de 1988. Diário Oficial [da] União, Brasília, DF, 5 out. 1988. Disponível em: < http://www2.camara.leg.br/legin/fed/ consti/1988/constituicao-1988-5-outubro-1988-322142-publicacaooriginal-1-pl.

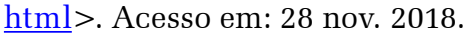

BRASIL. Câmara dos Deputados. Apoio à aprovação do projeto de lei da Escola sem Partido, com vistas ao combate da doutrinação nas escolas e à garantia constitucional da pluralidade do ensino [discurso proferido pelo deputado Rogério Marinho]. 7 fev. 2017. Disponível em: < https://goo.gl/4B7mg5>. Acesso em: 28 nov. 2018.

BRASIL. Câmara dos Deputados. PL 246/2019. Institui o "Programa Escola Sem Partido". 2019. Disponível em: < https://www.camara.leg.br/proposicoesWeb/fic hadetramitacao?idProposicao=2190752 > . Acesso em: 6 fev. 2019.

CASTILHO, Denis. Escola Sem Partido: a farsa do absurdo. Pragmatismo Político, 12 dez. 2018. Disponível em: <https://www.pragmatismopolitico.com. br/2018/12/escola-sem-partido-farsa.html>. Acesso em: 20 dez. 2018.

CASTILHO, Denis. O marxismo realmente se instalou nas escolas? Pragmatismo Político, 8 jan. 2019. Disponível em: <https://www.pragmatismopolitico.com. br/2019/01/marxismo-instalou-escolas-bolsonaro.html>. Acesso em: 9 jan. 2019.

CAVALCANTI, Lana S. Geografia, escola e construção de conhecimentos. 7. ed. Campinas, SP: Papirus, 1998.

CONVENÇÃO AMERICANA SOBRE DIREITOS HUMANOS. Comissão Interamericana de Direitos Humanos, [201-]. Disponível em: <https://www.cidh. oas.org/basicos/portugues/c.convencao americana.htm>. Acesso em: 28 nov. 2018.

DEPUTADA estadual do PSL eleita por SC incita alunos a filmar e denunciar professores. G1, 29 out. 2018. Disponível em: < https://g1.globo.com/sc/santacatarina/eleicoes/2018/noticia/2018/10/29/deputada-estadual-do-psl-eleita-porsc-incita-alunos-a-filmar-e-denunciar-professores.ghtml $>$. Acesso em: 2 nov. 2018.

DOLTON, Peter; MARCENARO, Oscar; DE VRIES, Robert; PO-WEN, She. Global Teacher Status Index 2018. London: Varkey Foundation, 2018. Disponível em: $<$ https://www.varkeyfoundation.org/media/4867/gts-index-13-11-2018.pdf $>$. Acesso em: 8 fev. 2019.

ESCOLA SEM PARTIDO - ESP. Por uma lei contra o abuso da liberdade de ensinar. [2018?]. Disponível em: <https://www.programaescolasempartido. org >. Acesso em: 27 nov. 2018.

HARVEY, David. O novo imperialismo. Tradução de Adail Sobral e Maria Stela Gonçalves. 2. ed. São Paulo: Loyola, 2005.

HUXLEY, Aldous. Admirável mundo novo. Tradução de Vidal de Oliveira e Lino Vallandro. 5. ed. Porto Alegre: Globo, 1979. 
INSTITUTO BRASILEIRO DE GEOGRAFIA E ESTATÍSTICA (IBGE). Módulo Educação da Pesquisa Nacional por Amostra de Domicílios. [2018]. Disponível em: <https://www.ibge.gov.br/estatisticas-novoportal/sociais >. Acesso em: 18 maio 2018.

INSTITUTO NACIONAL DE ESTUDOS E PESQUISAS EDUCACIONAIS ANÍSIO TEIXEIRA (INEP). Censo da Educação Básica 2018. Brasília, DF, 2019.

INVESTIMENTO em educação caiu 66\% nos últimos 5 anos. DCI, 7 maio 2018. Disponível em: <https://www.dci.com.br/servicos/investimento-em-educac-ocaiu-66-nos-ultimos-5-anos-1.704521>. Acesso em: 28 nov. 2018.

KROPOTKIN, Piotr. Ajuda mútua: um fator de evolução. Tradução de Waldyr Azevedo Jr. São Sebastião: A Senhora Editora, 2009.

KROPOTKIN, Piotr. O que a geografia deveria ser. In: RECLUS, Élisée; KROPOTKIN, Piotr. Escritos sobre educação e geografia. Tradução de Rodrigo Rosa da Silva, Guilherme Amaral e Adriano Skoda. São Paulo: Biblioteca Terra Livre, 2014. p. 33-72.

MAIORIA dos municípios não paga o piso salarial aos professores, diz MEC. G1, 13 jan. 2017. Disponível em: < https://g1.globo.com/educacao/noticia/maioriados-municipios-nao-paga-o-piso-salarial-aos-professores-diz-mec.ghtml $>$. Acesso em: 8 dez. 2018.

MANUAL de Defesa Contra a Censura nas Escolas. 2018. Disponível em: $<\underline{\text { http:// }}$ www.manualdedefesadasescolas.org/manualdedefesa.pdf $>$. Acesso em: $8 \mathrm{dez}$. 2018.

MARX, Karl. O capital - crítica da economia política, IV: Teorias da mais-valia: a história crítica do pensamento econômico. Tradução de Reginaldo Sant'Anna. São Paulo: Difel, 1980. v. I, II e III.

MARX, Karl. O capital - crítica da economia política, I: O processo de produção do capital. Tradução de Rubens Enderle. São Paulo: Boitempo, 2011.

MARX, Karl. O capital - crítica da economia política, II: O processo de circulação do capital. Tradução de Rubens Enderle. São Paulo: Boitempo, 2014.

MARX, Karl. O capital - crítica da economia política, III: O processo global da produção capitalista. Tradução de Rubens Enderle. São Paulo: Boitempo, 2017.

NA VÉSPERA da posse, Bolsonaro critica "lixo marxista" em escolas. UOL, 31 dez. 2018. Disponível em: <https://noticias.uol.com.br/politica/ultimasnoticias/2018/12/31/bolsonaro-marxismo-escolas.htm $>$. Acesso em: $31 \mathrm{dez}$. 2018.

OLIVETO, Paloma. Professores relatam ameaças por conta do Projeto Escola Sem Partido. Correio Brasiliense, 19 nov. 2018. Disponível em: <https://www. correiobraziliense.com.br/app/noticia/brasil/2018/11/19/interna-brasil,720153/ professores-relatam-ameacas-por-conta-do-projeto-escola-sem-partido.shtml $>$. Acesso em: 8 dez. 2018.

ORGANIZAÇÃO para a Cooperação e Desenvolvimento Econômico - OCDE. Education at a Glance 2018 - um olhar sobre a educação. Portal ODS, 2018. 
Disponível em: <http://portalods.com.br/publicacoes/education-at-a-glance2018-um-olhar-sobre-a-educacao $>$. Acesso em: 27 nov. 2018.

ORWELL, George. 1984. Tradução de Alexandre Hubner e Heloisa Jahn. 37. reimp. São Paulo: Companhia das Letras, 2009.

PORTAL DA TRANSPARÊNCIA. Educação [despesas]. 2018. Disponível em: $<$ http://www.portaltransparencia.gov.br/funcoes/12-educacao?ano=2018 $>$. Acesso em: 25 jan. 2019.

RATIER, Rodrigo. 14 perguntas e respostas sobre o "Escola Sem Partido". In: SOUZA, Ana Lúcia et al. (Org.). A ideologia do movimento Escola Sem Partido. São Paulo: Ação Educativa, 2016. p. 29-42.

VYGOTSKY, Lev S. A formação social da mente. Tradução de José Cipolla Neto, Luís Silveira Menna Barreto e Solange Castro Afeche. São Paulo: Martins Fontes, 1984.

XIMENES, Salomão. O que o Direito à Educação tem a dizer sobre "Escola Sem Partido"? In: SOUZA, Ana Lúcia et al. (Org.). A ideologia do movimento Escola Sem Partido. São Paulo: Ação Educativa, 2016. p. 49-58.

Denis Castilho - possui doutorado em Geografia pela Universidade Federal de Goiás, com estagio doutoral na Universidad de Barcelona. Atualmente é professor dos cursos de Graduação e Pós-Graduação do Instituto de Estudos Socioambientais da UFG. (iD https://orcid.org/0000-0002-2467-1189 